\title{
Venturing into drug discovery
}

\author{
Biotechnology now has an established role in drug discovery, \\ but the best opportunities are yet to come.
}

\begin{abstract}
Michael Steinmetz
When I was a graduate student in the early 1970s, there was a general feeling among my colleagues that most of the exciting discoveries in molecular biology had already been made. The structure of the DNA double helix had been worked out, the genetic code deciphered, the mecha-
\end{abstract} nism of gene transcription and protein synthesis identified. All that was left for us to do, the next generation of molecular biologists, was to work out the details. We were born too late!

How wrong we were. The next 20 years brought the development of recombinant DNA technology, its application to the analysis of gene structure and function, and an explosion of new biological information. With it came the emergence of the biotechnology industry and a growing understanding of molecular mechanisms that led to the identification of new targets for disease intervention.

\section{Biotechnology's pivotal role}

Drug discovery is the translation of basic biological findings into innovative medicines. From its very beginning, the pharmaceutical industry has been built around research results obtained in academia. Prominent examples of drugs that came out of academic research include antibiotics such as penicillin and streptomycin, insulin, and vitamins.

Today, the biotechnology industry has largely replaced the pharmaceutical companies' interaction with academia and has become the intermediary to the pharmaceutical industry. Many scientists, especially in the United States, seem to prefer to channel their discoveries, product ideas, and technology developments into biotechnology. There are a number of reasons for this: It is often easier for academic scientists to find the attention of people in the biotechnology industry, the ties are closer, there are fewer bureaucratic hurdles, the innovation intensity is higher, and it is potentially financially more rewarding to be involved in a startup company with shares or stock options.

Michael Steinmetz is managing director of MPM Asset Management, One Cambridge Center, 9th Floor, Cambridge MA 02142 (msteinmetz@mpmcapital.com).
Biotechnology's role of validating and developing these academic discoveries has made it an extremely technologically diverse industry. All aspects of drug discovery-from drug target identification and validation to lead finding and optimization-are covered. Product-focused companies work not only on recombinant protein therapeutics, but also small molecules therapeutics, as well as gene, antisense, and cell therapeutics. Socalled tool companies offer such enabling technologies as genomics, combinatorial chemistry, high-throughput screening, and bioinformatics.

Given this broad diversity, even the largest pharmaceutical companies can no longer build a sufficiently strong research base to cover all therapeutic areas and all technical advances in drug discovery. As a result, pharmaceutical companies realize that it makes good sense to collaborate with biotechnology in order to explore and exploit what is available. It is, therefore, no surprise that from 1993 to 1997, the number of new alliances per year has more than tripled, with the total value of these new deals having grown from $\$ 1.4$ to $\$ 4.5$ billion'. This trend is likely to continue when companies as large as Novartis (Basel, Switzerland) have declared their intent to invest up to $30 \%$ of their research budget in biotechnology alliances. This makes the future opportunities for the most innovative biotechnology companies look abundant.

\section{The new profile}

What is required to build a biotechnology company? Conventional wisdom tells us that the science and technology base has to be strong and sufficiently mature, that there has to be a good business strategy, an attractive market opportunity, a reasonable proprietary position, and the right people. What is most important? The quality of the people. We are looking for people who have succeeded in different environments, show tenacity, have a sense of urgency, are pragmatic, and can identify the nonobvious. In addition, they have to be team players. Nobody can succeed in today's complex research and business environment by himself or herself alone. And finally, every scientist who joins a biotechnology company has to realize that the name of the game is no longer just exciting science and technology but a product - be it a discovery tool or a drug - that can generate and sustain a profitable business.

In this regard, while the industry in the United States has come of age, it has only just started in Europe. It is therefore not surprising that biotechnology in Europe behaves like a newborn, making many mistakes, but learning fast and being adored by everybody. We want the fledgling European biotechnology industry to succeed. The big question is, will it be able to compete with its big brother in the United States, and will it find the necessary financial support from the pharmaceutical industry, especially those pharmaceutical companies with a research base in Europe?

Being able to work closely with a biotechnology partner in the vicinity is a big plusbut more important for big pharma is the quality of the people and the technology being offered. Although I am of the opinion that European-based pharmaceutical companies have a social responsibility to support the biotechnology effort in Europe through collaborations and alliances-I know, in the end, it is a business decision.

\section{Conclusions}

I am often asked whether there are still attractive possibilities for new biotechnology companies or whether the best opportunities are already gone. My answer is, and has always been, "The best is still to come." Science and technology are becoming more complex and new people with new ideas and no existing ties to established companies will be needed to develop them. I see the previous successes of the biotechnology industry much as I now view the discoveries my graduate school colleagues and I once debated: They are only the foundation for discoveries of which we are not yet able to even dream.

1. BioWorld Financial Watch. March 30, 1998. 6(13). 